Supplement of The Cryosphere, 15, 1277-1284, 2021

https://doi.org/10.5194/tc-15-1277-2021-supplement

(C) Author(s) 2021. This work is distributed under

the Creative Commons Attribution 4.0 License.

(c) (1)

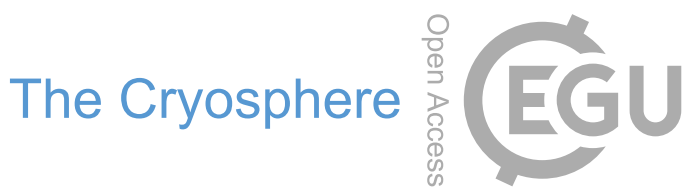

Supplement of

\title{
Estimating parameters in a sea ice model using an ensemble Kalman filter
}

Yong-Fei Zhang et al.

Correspondence to: Yong-Fei Zhang (yfzhang.nju@gmail.com)

The copyright of individual parts of the supplement might differ from the CC BY 4.0 License. 


\section{Supplemental figures}

2005-06-01

(a)

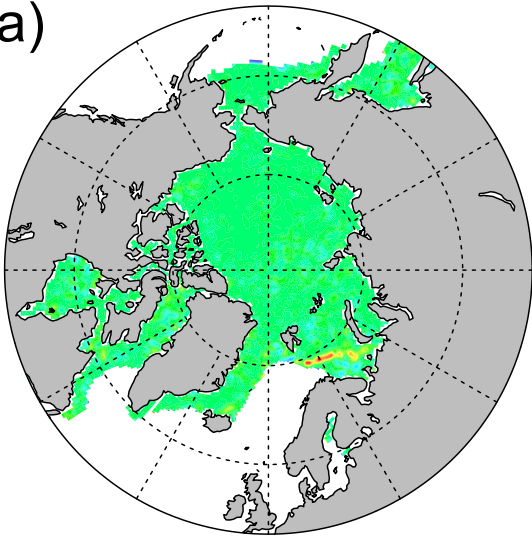

2005-08-01

(b)

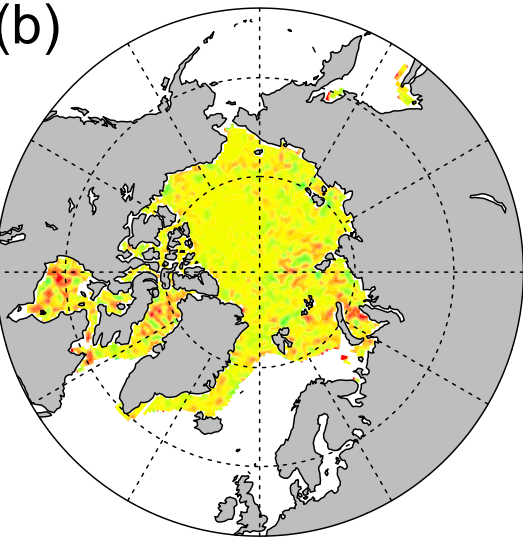

2005-10-01

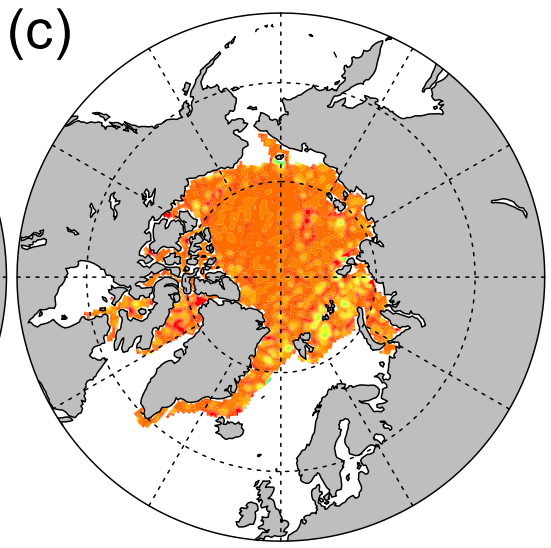

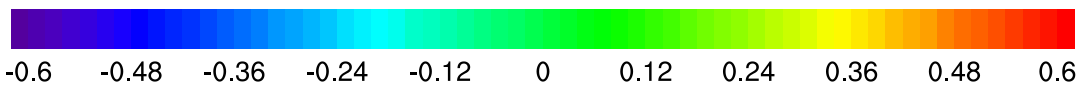

(d)

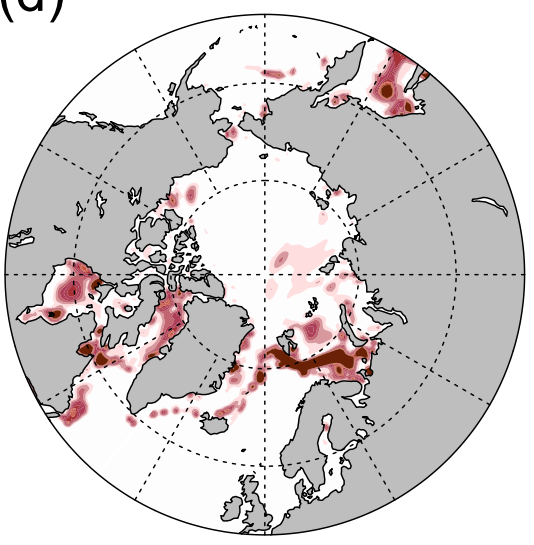

(e)

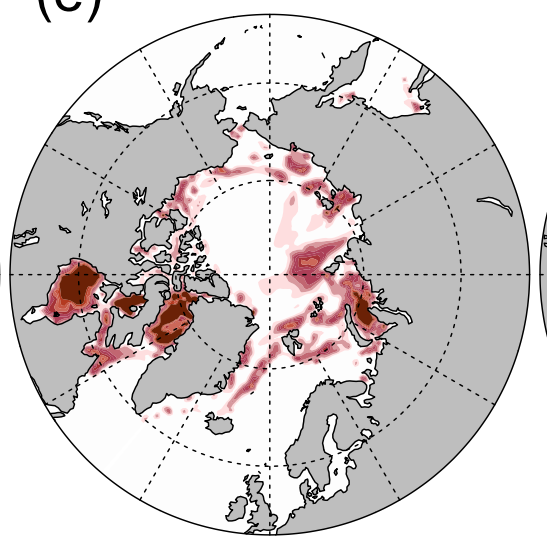

(f)

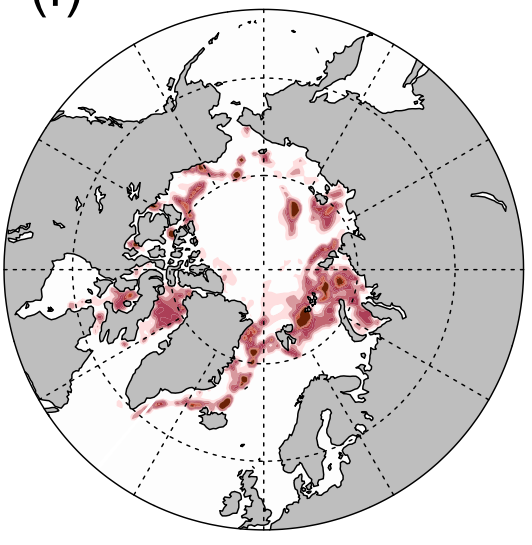

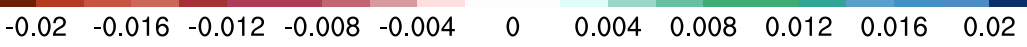

Figure $\mathrm{S} 1$. The posterior values of $\mathrm{R}_{\mathrm{snw}}$ for the experiment DAsitPEcst on (a) 2005-06-01,

(b) 2005-08-01, and (c) 2005-10-01, and the differences between the ensemble spread of posterior $\mathrm{R}_{\mathrm{snw}}$ and that of prior $\mathrm{R}_{\mathrm{snw}}$ (the posterior minus prior) for the experiment DAsitPEcst on (d) 2005-06-01, (e) 2005-08-01, and (f) 2005-10-01. 